\title{
DESIGN AND TESTING OF FLIGHT CONTROL LAWS ON THE RASCAL RESEARCH HELICOPTER
}

\author{
Chad R. Frost ${ }^{*}$ \\ William S. Hindson ${ }^{\dagger}$ \\ Ernesto Moralez, III ${ }^{\ddagger}$ \\ George E. Tucker ${ }^{\S}$ \\ U.S. Army/NASA Rotorcraft Division \\ NASA Ames Research Center, Moffett Field, CA \\ James B. Dryfoos" \\ The Boeing Company, Miltary Aircraft and Missile Systems Division \\ Philadelphia, PA
}

\begin{abstract}
Two unique sets of flight control laws were designed, tested and flown on the Army/NASA Rotorcraft Aircrew Systems Concepts Airborne Laboratory (RASCAL) JUH-60A Black Hawk helicopter. The first set of control laws used a simple rate feedback scheme, intended to facilitate the first flight and subsequent flight qualification of the RASCAL research flight control system. The second set of control laws comprised a more sophisticated model-following architecture. Both sets of flight control laws were developed and tested extensively using "desktop-to-flight" modeling, analysis, and simulation tools. Flight test data matched the modelpredicted responses well, providing both evidence and confidence that future flight control development for RASCAL will be efficient and accurate.
\end{abstract}

\footnotetext{
Aeronautical Engineer, cfrost@mail.arc.nasa.gov. Senior Member, AIAA.

$\dagger$ RASCAL Project Manager, bhindson@mail.arc.nasa.gov.

* Aeronautical Engineer, emoralez@mail.arc.nasa.gov. Member, AIAA.

$\S$ RASCAL Research Pilot, gtucker@mail.arc.nasa.gov.

- Manager, Flight Controls and Flying Qualities, RAH-66 Comanche Program, james.b.dryfoos@boeing.com.
}

Copyright (C) 2002 by the American Institute of Aeronautics and Astronautics, Inc. No copyright is asserted in the United States under Title 17, U.S. Code. The U.S. Government has a royalty-free license to exercise all rights under the copyright claimed herein for Governmental purposes. All other rights are reserved by the copyright owner.

\section{Introduction}

This paper describes the development and testing of two unique sets of flight control laws for the Army/NASA Rotorcraft Aircrew Systems Concepts Airborne Laboratory (RASCAL). One set of control laws can be characterized as response-feedback, while the other is a model-following concept.

RASCAL (Figure 1) is a Sikorsky JUH-60A Black Hawk helicopter, modified for research by the addition of a programmable high-bandwidth full-authority research flight control system (RFCS). Modifications include parallel hydraulic actuators, a highly capable flight control computer, a transfer system whereby control is transferred between the safety pilot and the fly-by-wire system, and replacement of the right-seat pilot inceptors (cyclic, pedals, and collective) with a three-axis sidearm controller and electrically backdriven collective. Full details of RASCAL's configuration may be found in Ref. 1 .

RASCAL has been developed by the Army and NASA as a highly flexible research platform capable of exploring a wide range of flight control, cockpit display, and related system configurations. The flight control research capabilities are supported by an extensive set of desktop and ground simulation tools that together ensure efficient, rapid, and safe flight testing of new concepts. RASCAL can also be viewed as a variable-stability in-flight simulator, for which the model-following control laws to be described in this paper are especially suited.

\section{Flight Control Development Process}

Desktop-to-Flight Development Environment

The Army/NASA Rotorcraft Division has developed a set of software tools enabling designers to 


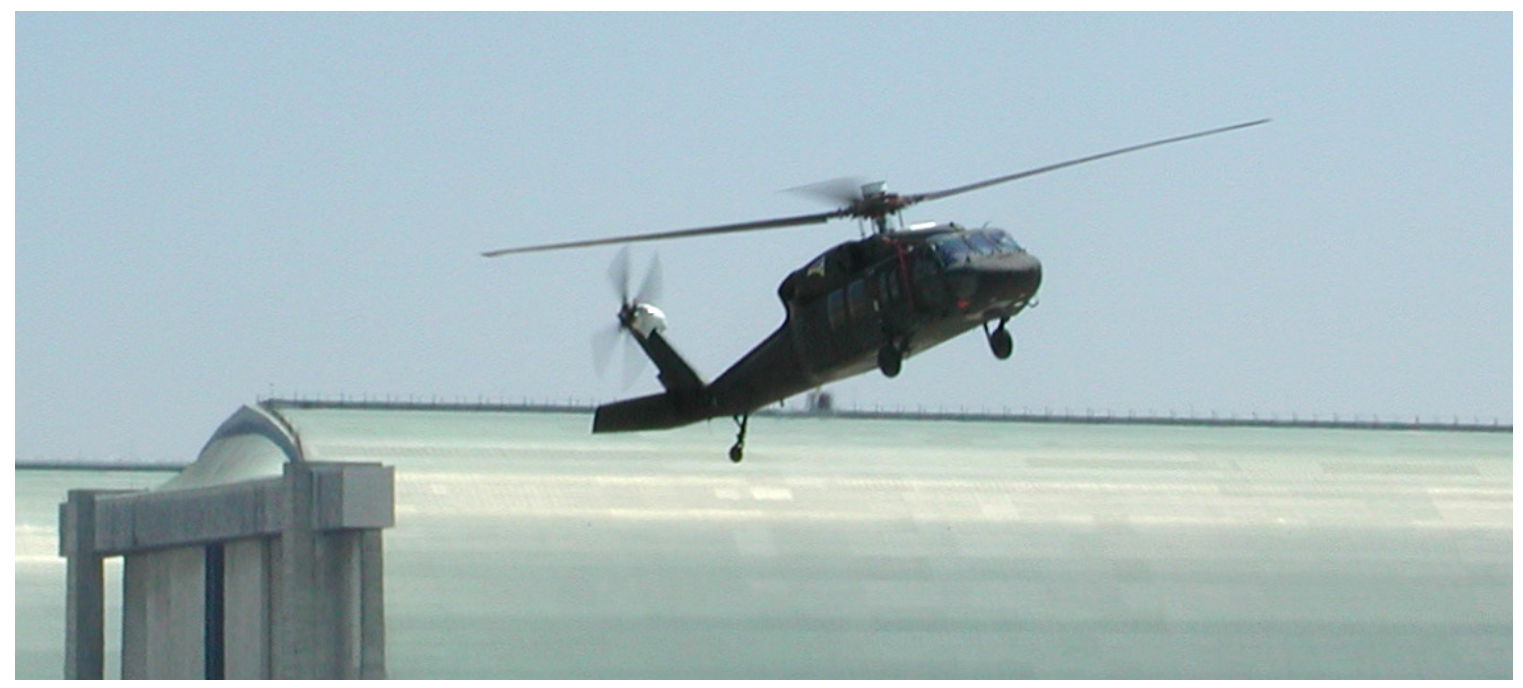

Figure 1. RASCAL JUH-60A Black Hawk

take a flight control concept from inception to flight test in an efficient and reliable process.

The first step in the process is the selection of a math model of the aircraft dynamics. In the case of RASCAL, 6-degree-of-freedom (DOF) and 10-DOF linear models of the unaugmented UH-60 at a variety of flight conditions have been previously identified ${ }^{2}$ from flight test data using the Comprehensive Identification from Frequency Responses $\left(\mathrm{CIFER}^{\circledR 3}\right)$ software. In addition, a validated non-linear real-time simulation code (GenHel) is available, ${ }^{4}$ enabling the robustness of a control system design to be subsequently evaluated throughout the entire flight envelope.

Control loops are then designed around the linear math model using the MATLAB / Simulink ${ }^{\circledR}$ control system modeling tools and the Control Designer's Unified Interface (CONDUIT ${ }^{\circledR}$ ) analysis/optimization environment. $^{5}$ CONDUIT $^{\circledR}$ is used to evaluate and optimize the control law gains to simultaneously meet a broad variety of stability, performance, and handlingquality specifications, as well as certain hardware limitations such as actuator rate capabilities.

The resulting closed-loop models may be flown in a workstation-based, real-time, piloted simulation (the Real-time Interactive Prototype Technology Integration/Development Environment, RIPTIDE) to evaluate qualitative aspects such as control sensitivity and control mode transitions. ${ }^{6}$ The RIPTIDE facility at NASA Ames is equipped with a panoramic projection display system and an electromechanical backdriven cyclic controller to provide additional fidelity to this otherwise low-cost fixed-base piloted simulation tool.

Final checkout and pilot familiarization with the control laws is accomplished using the RASCAL Development Facility's hardware-in-the-loop simulator, ${ }^{7}$ which includes the flight control computer, evaluation pilot interface, and high-fidelity real-time non-linear simulations of the RASCAL research flight control actuators, sensors, and UH-60 dynamics.

Prior to approval of the flight control software for release to the aircraft, it undergoes a controlled test and evaluation sequence in the Development Facility (DF), after which it is loaded into the aircraft's flight control computer. Once the basic functionality of the software has been checked in flight, the flight control laws are validated by recording closed-loop piloted doublets and/or frequency sweeps. These flight test data are then analyzed using CIFER $^{\circledR}$ to extract frequency responses. The flight test time histories and frequency responses can then be compared to the responses predicted by the simulation model.

RASCAL is the first in-house Army/NASA program to utilize the full suite of desktop-to-flight tools. However, the preceding description of the desktop-to-flight process has been proven out in several recent flight vehicle development activities conducted with industry partners, including the Kaman Aerospace Broad-area Unmanned Responsive Resupply Operations (BURRO) 6000-lb unmanned helicopter, ${ }^{8}$ the Northrop-Grumman/Schweitzer Fire Scout Vertical Take-off Unmanned Aerial Vehicle (VTUAV), ${ }^{9}$ and the Microcraft iStar 9-inch diameter unmanned vehicle. ${ }^{10}$

\section{$\underline{\text { RASCAL Flight Control Computer }}$}

The RASCAL Research Flight Control Computer Assembly (RFCCA) is divided into two physically segregated elements: a Flight Control Computer (FCC) and a Servo Control Unit (SCU). This architecture allows a great deal of freedom in the development and testing of new flight control laws, while protecting the aircraft and systems from any unforeseen anomalies in those control laws, or in system operation. A summary of the RFCCA is provided here, while greater detail is available in Ref. 1. 
The SCU is a dualized system that comprises the RFCCA's interface to the aircraft and is responsible for monitoring the RFCS for safe operation. The SCU operates with the assumption that a hardware failure, sensor failure or flight control law failure could occur at any time, and continuously monitors a wide variety of parameters. The SCU's monitoring software detects and captures failures that would generate unacceptably large flight control transients, and in such an event reverts the aircraft to safety pilot control in less than $100 \mathrm{~ms}$. The design criteria for the monitors were established through piloted simulation research conducted at Ames using the Vertical Motion Simulator; details may be found in Ref. 11. Functional testing, fine-tuning, and validation of the monitors was accomplished in the RASCAL DF as well as on the aircraft.

The FCC hosts the flight control law code. The FCC is a single-channel system. A basic set of software elements provides a standardized interface to sensor data, pilot inputs and aircraft actuator outputs for implementation of flight control laws. This allows the flight control law development to take place at a high level, without requiring knowledge of the implementation details of each system interface. For example, commands generated by the FCC are in "pilot axes", i.e. inches of equivalent UH-60 inceptor displacement, which the SCU translates through a software representation of the Black Hawk's mechanical mixing box into "servo axes", i.e. inches of displacement of the forward, aft and lateral research servos driving the UH-60 primary servos (and in turn the swashplate) as well as the tail research servo that drives the tail rotor primary servo. Because the translation from pilot axes to servo axes is handled in the SCU, it is transparent to the flight control developer, who needs only to be concerned with producing control law commands in "pilot axes".

\section{Baseline Control Law Development}

An initial set of control laws was designed expressly for the first flight and system qualification phase of the RASCAL RFCS. These "baseline" control laws were intentionally simple, consisting of only the minimum elements needed to provide basic stability augmentation in a manner compatible with the RASCAL sidestick inceptor. The rationale for using simple control laws for the earliest work on the aircraft was that any anomalous behavior of the overall RFCS would be easier to identify, and comparison of the aircraft response to that of the simulation model would be more straightforward.

The baseline control laws therefore included only rate feedbacks to pitch, roll and yaw; collective was "direct-drive" from the RASCAL inceptor. Low-gain integrators in pitch, roll and yaw provided trim followup, which slowly trimmed the sidestick to center position as the aircraft trim state varied with flight condition. Synchronization of the control law output with the safety pilot controls was provided to prevent transient behavior at the instant of RFCS engagement. Figure 2 illustrates the architecture of the pitch channel, which is representative of the roll and yaw axes.

The control laws included limiters on authority, rate, and the trim integration; the rate limits, as well as most system gains, were manually adjustable in-flight via the RASCAL cockpit's Control/Display Unit (CDU).

To accurately represent the dynamics of the total system, it is essential to include the high frequency elements. In the case of helicopters, the delay introduced by these elements (in particular, the main rotor) is a key limiting factor for the achievable bandwidth of the flight control system. ${ }^{12}$ The contributing elements in the RASCAL RFCS are listed in Table 1.

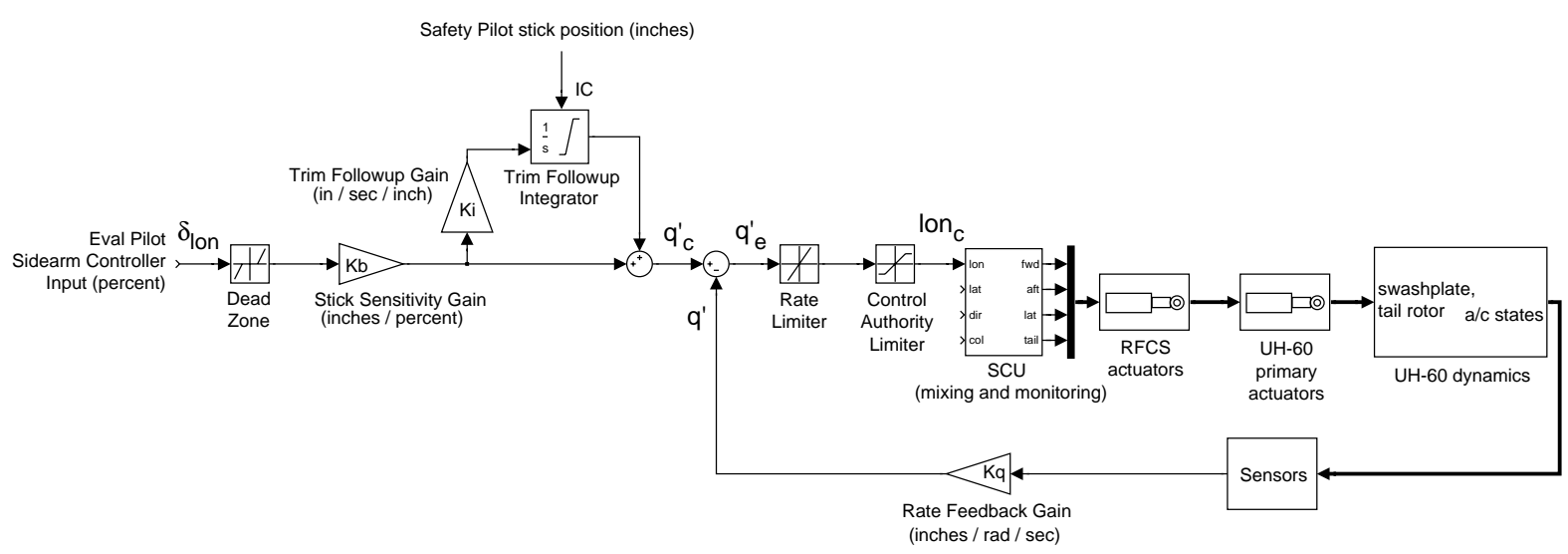

Figure 2. Baseline control law concept, pitch channel shown 
Table 1. Sources of forward-path delay

Estimated equivalent time delay (ms)

\begin{tabular}{|c|c|c|c|}
\hline $\begin{array}{c}\text { System } \\
\text { Element }\end{array}$ & Longitudinal & Lateral & Directional \\
\hline $\begin{array}{l}\text { Biodynamic } \\
\text { filters on } \\
\text { inceptor } \\
\text { inputs }\end{array}$ & 64 & 29 & 29 \\
\hline $\begin{array}{l}\text { Anti-alias } \\
\text { filters }\end{array}$ & 11 & 11 & 11 \\
\hline $\begin{array}{l}\text { FCC } \\
\text { computations }\end{array}$ & 4.9 & 4.9 & 4.9 \\
\hline $\begin{array}{l}\text { Zero-order } \\
\text { hold }\end{array}$ & 2 & 2 & 2 \\
\hline $\begin{array}{l}\text { SCU } \\
\text { computations }\end{array}$ & 0.2 & 0.2 & 0.2 \\
\hline $\begin{array}{l}\text { Research } \\
\text { actuator } \\
\text { digital loop } \\
\text { closure }\end{array}$ & 0.7 & 0.7 & 0.7 \\
\hline $\begin{array}{l}\text { RFCS } \\
\text { actuators }\end{array}$ & 14 & 14 & 14 \\
\hline $\begin{array}{l}\text { Primary } \\
\text { actuators }\end{array}$ & 13 & 13 & 13 \\
\hline Rotor & 66 & 66 & -- \\
\hline TOTALS & 176 & 141 & 75 \\
\hline
\end{tabular}

The initial values of the control system gains were designed using total system models of the aircraft at the hover, 80 knot and 130 knot flight conditions. The system models included 6-DOF linear models of the UH-60 rigid-body dynamics, with second-order nonlinear models of the RASCAL RFCS actuators and UH-60 primary actuators, and Padé approximations of the sensor and computational delays. Models of the sensor filters to be used in the aircraft were also included. CONDUIT was used to analyze the brokenloop, on-axis frequency responses for each of the three flight conditions to select the rate feedback gains. Modest crossover frequencies in the range of $2-3$ $\mathrm{rad} / \mathrm{sec}$ were selected to avoid excitation of unmodeled rotor and structural modes, while attempting to maintain the MIL-HDBK-1797 stability margin guidelines of $45 \mathrm{deg}$ phase margin and $6 \mathrm{~dB}$ gain margin. ${ }^{13}$ A single set of gains was selected to cover all flight conditions.

Control authority limits were set to approximate the control throws of the UH-60's mechanical flight controls, although in practice the SCU control limit monitors were reached first. The trim integrators were limited to prevent wind-up; the limits were chosen to maintain $20 \%$ control margin, at the expense of reduced trim authority. The resulting gains were, incidentally, a good approximation of the responses of the ratefeedback portion of the UH-60 stability augmentation system.

During the course of flight testing, a lightly-damped aeroservoelastic mode at about $6.5 \mathrm{~Hz}$ was observed in forward flight with sustained load factor, such as during turns and pull-ups. The pitch rate sensor filter was subsequently adjusted to a lower cutoff frequency (3 $\mathrm{Hz}$ ) to increase attenuation at the modal frequency. This eliminated the resonance.

Early in the test program, records of piloted doublet maneuvers were obtained and analyzed using CIFER $^{\circledR}$ to check the accuracy of the model predictions. As seen in Figure 3, the modeled response is a reasonable match to the flight-identified response, despite the limited frequency content of the doublet control input. Piloted frequency sweeps were also obtained and the identified frequency responses generally matched the model predictions well. Once the basic system performance was validated, the focus of the project was placed on bringing the more advanced set of control laws onto the aircraft.

\section{Advanced Control Law Development}

RASCAL's advanced control laws were developed by Boeing Helicopter, and have Advanced DigitalOptical Control System (ADOCS) and RAH-66 Comanche heritage. ${ }^{14,15,16}$ The control law software was generated using Boeing-proprietary pictures-tocode algorithms. That code has, to date, been utilized in the RASCAL flight control computer, but the control laws have also been ported to Simulink ${ }^{\circledR}$ for parallel use in the project's desktop-to-flight tools.

These control laws were intended to be a robust and stable foundation for system validation, and to provide flexibility for future development; ${ }^{1}$ they are of an explicit model-following architecture.

\section{Model-Following Concept}

A brief overview of the characteristics of a modelfollowing control system is provided here to help those unfamiliar with the concepts understand the discussion that follows; much more thorough treatments may be found in References 17 and 18. Model-following control systems are typically comprised of feedback compensation $\mathrm{H}(\mathrm{s})$ to stabilize the vehicle and reject 

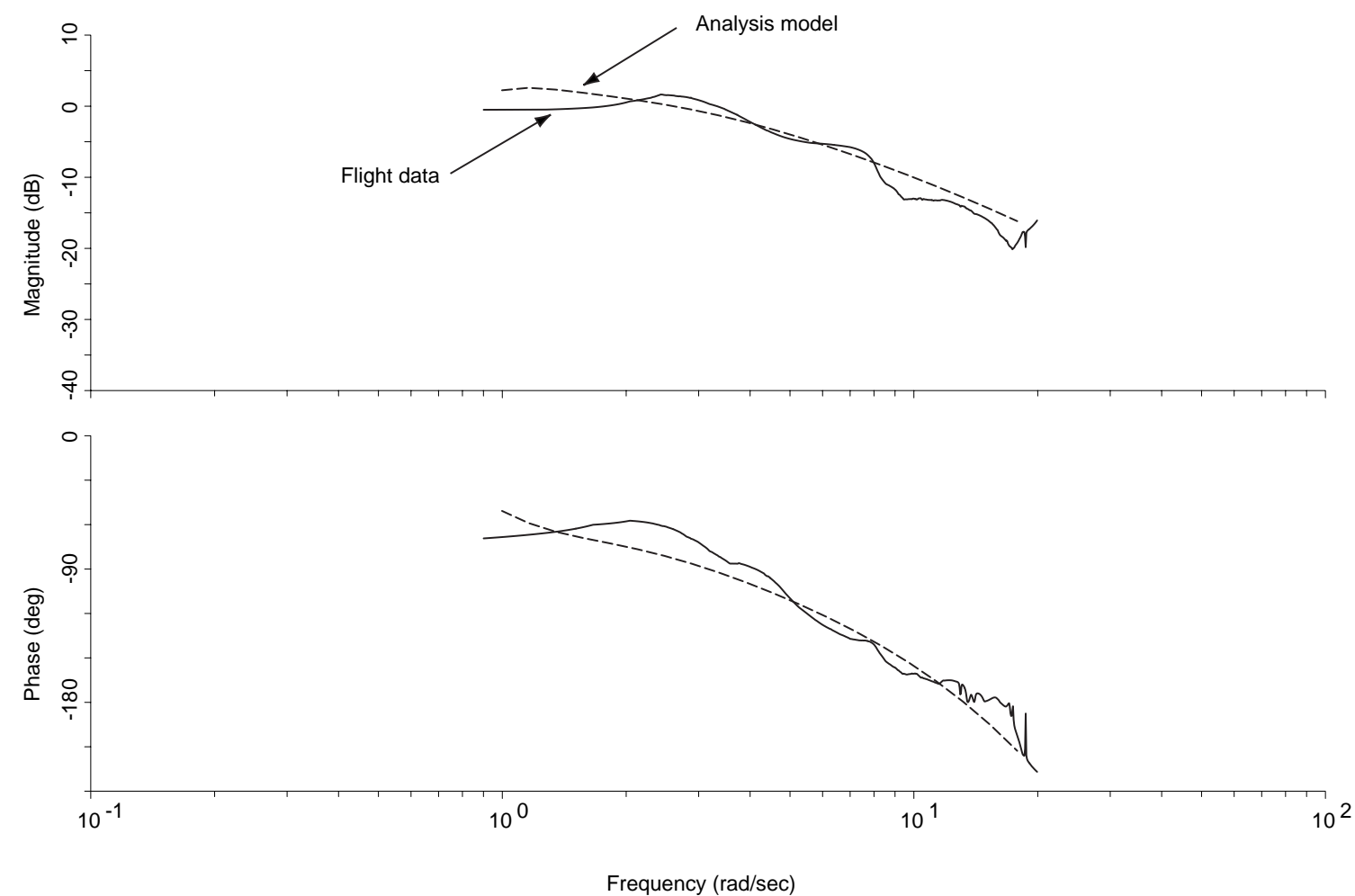

Figure 3. Comparison of closed-loop pitch responses extracted from flight-test, baseline control law, 80kts

A) Model-following architecture as implemented in RASCAL:

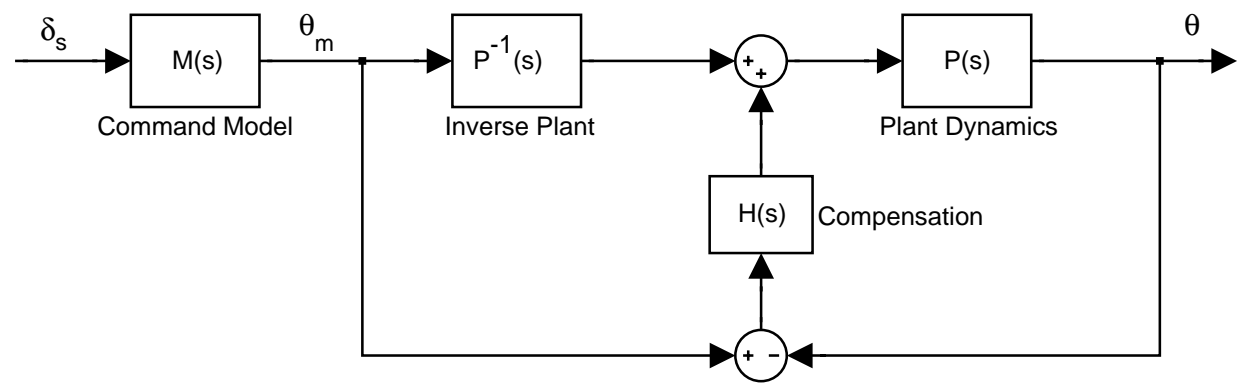

B) Equivalent architecture for purposes of analysis:

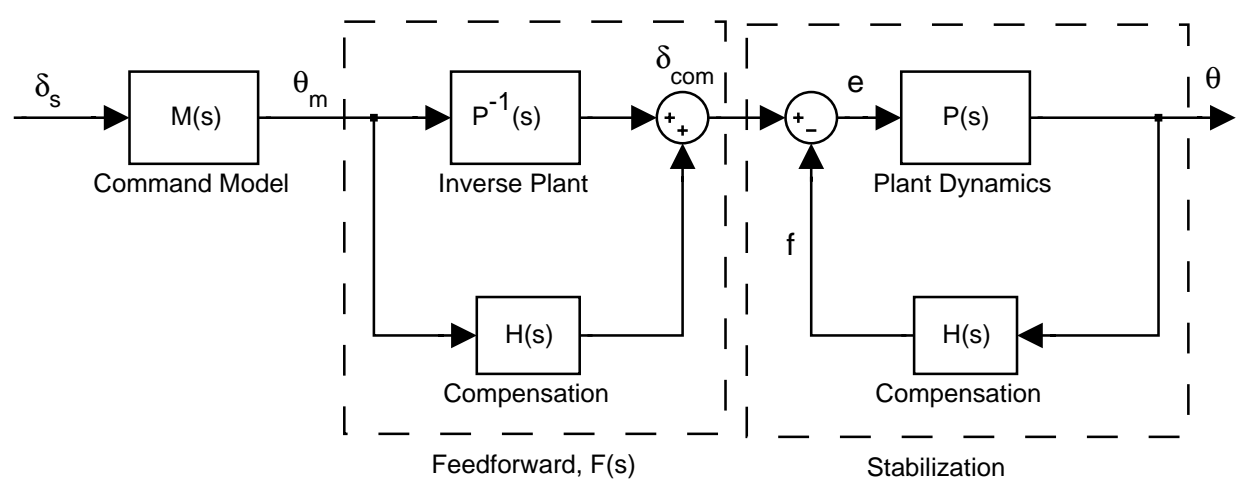

Figure 4. Model-following concept 
disturbances, a feedforward element $F(s)$ consisting of an inverse model of the aircraft dynamics $\mathrm{P}^{-1}(\mathrm{~s})$ together with a model of the feedback compensation $\mathrm{H}(\mathrm{s})$, and a command model $\mathrm{M}(\mathrm{s})$. These elements are illustrated conceptually in Figure 4. For purposes of analysis, the architecture of Figure $4 \mathrm{~A}$ can be reorganized as shown in Figure 4B. Combined, the stabilization and feedforward portions produce a transfer function of unity:

$$
\frac{\theta}{\theta_{m}}(s)=\left[P^{-1}(s)+H(s)\right] \cdot \frac{P(s)}{1+P(s) H(s)}=1
$$

Assuming a perfect and realizable inverse model of the aircraft $\mathrm{P}^{-1}(\mathrm{~s})$ is available, the vehicle response $\theta$ will exactly track the model response $\theta_{\mathrm{m}}$. In practice, it is not feasible to attempt to cancel the high-frequency dynamics such as those associated with the rotor and actuators. At the same time, low-frequency characteristics such as aerodynamic trim effects or weight or center of gravity effects that are not completely cancelled can be easily suppressed by the stabilization loop. Therefore, simple first- or secondorder representations usually suffice for the inverse model.

Because the aircraft's principal inherent modes are cancelled, the desired dynamic response may be introduced as the command model M(s). From Figure 4, it is evident that the model-following architecture provides a high level of modularity and lends itself to incremental evolution and development. Changing a command model does not necessitate changing the

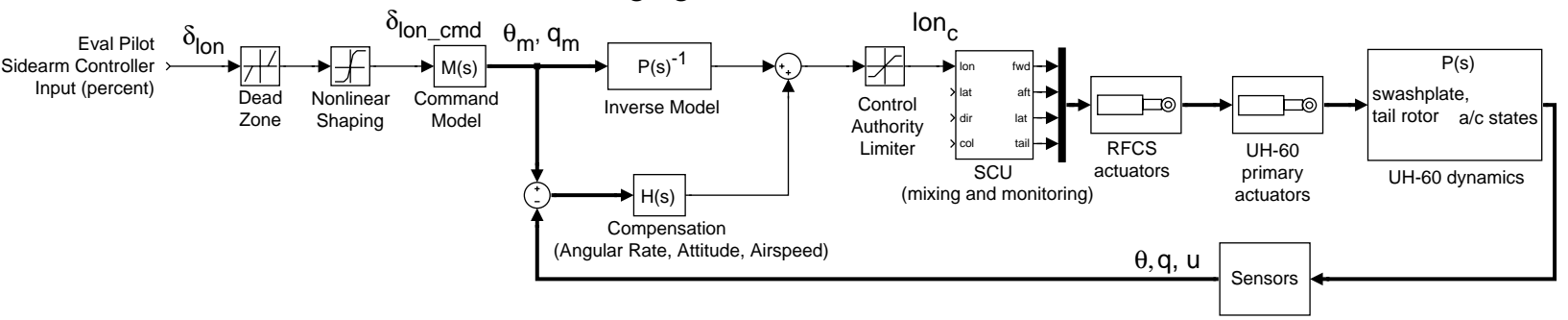

Figure 5. Model-following control law implementation

Table 2. Advanced control law modes

\begin{tabular}{|c|c|c|c|c|}
\hline Airspeed & $<40 \mathrm{kts}$ & $40 \mathrm{kts}$ & $45 \mathrm{kts}$ & $>50 \mathrm{kts}$ \\
\hline Longitudinal & $\begin{array}{l}\text { ACAH + trim } \\
\text { follow-up }\end{array}$ & $\mathrm{ACVH}$ & & \\
\hline \multirow[t]{2}{*}{ Lateral } & \multirow{2}{*}{$\begin{array}{l}\text { ACAH + trim } \\
\text { follow-up }\end{array}$} & \multicolumn{3}{|c|}{$\rightarrow \mathrm{RCAH}$} \\
\hline & & \multicolumn{3}{|c|}{$\leftarrow$ RCAH until airspeed $<40$ KTS and wings level } \\
\hline \multirow[t]{2}{*}{ Directional } & \multirow[t]{2}{*}{$\mathrm{RCDH}$} & & & $\begin{array}{l}\rightarrow \mathrm{RCDH}+\text { Turn } \\
\text { Coordination }\end{array}$ \\
\hline & & \multicolumn{3}{|c|}{$\leftarrow \mathrm{RCDH}+$ Turn Coord until airspeed $<40 \mathrm{KTS}$} \\
\hline Collective & \multicolumn{4}{|c|}{ Direct Drive } \\
\hline
\end{tabular}


( $\mathrm{RCDH})$ with automatic turn coordination. The transition is accomplished through a combination of switching the command model from second-order to first-order (in the case of roll) and blending in the additional stabilization loops (in the case of airspeed hold and turn coordination.) Table 2 summarizes the control modes and transitions.

The control law architecture also has provisions for transitioning to and from a ground-taxi mode, but current research plans encompass only airborne operations.

As discussed above, the feedforward dynamics include an approximation of the inverse of the aircraft dynamics. The inverse model is of low order and is not varied with flight condition; instead, trim maps and the inherent low-frequency cancellation characteristics of feedback are used to accommodate these changes in the aircraft characteristics across a range of airspeeds.

\section{MFCL Testing}

Prior to flight testing, the MFCL were tested extensively, first in a piloted simulation at Boeing Philadelphia ${ }^{1}$, then in a desktop simulation using RIPTIDE, and finally in the RASCAL DF, to evaluate flight control modes, mode transitions, control sensitivities, and expected flight envelope.

Because the feedforward dynamics inherent to the model-following configuration drive the servo actuators much more aggressively than did the simple baseline control laws, it was anticipated that the SCU rate monitors might be more frequently tripped. This did not prove to be the case. In practice, pilot inputs were smoothed by the mechanical damping built into the sidestick inceptor, and normal maneuvering has not produced nuisance trips of the monitors.

Following the first MFCL flight, operational envelope expansion flights were conducted, first to evaluate the hover/low-speed performance in which the MFCL paths are simplest, followed by the high-speed regimes, which bring in turn coordination and airspeed hold functions, and then finally to fly through the complex mode transitions between 40 and $60 \mathrm{kts}$.

Research pilots found the MFCL preferable to the simple control laws in several respects. The MFCL decouples the aircraft response much more effectively, and provides very robust airspeed hold and turn coordination. Some aspects must be improved, e.g. roll and yaw sensitivities in forward flight are not wellharmonized with the pitch response.

\section{MFCL Analysis}

Hover frequency sweeps and doublets were performed to collect data for analysis. Three frequency sweeps were obtained in each of the longitudinal, lateral and directional axes. Because the vertical axis is a direct drive from the research inceptor and therefore closely matches the behavior of the standard Black Hawk, collective sweeps were not conducted.

The resulting data were analyzed using CIFER $^{\circledR}$ to identify the on-axis pitch, roll and yaw attitude frequency responses. The equivalent frequency responses of the CONDUIT simulation model were also generated. The comparison plot for the pitch response, shown in Figure 6, illustrates the good match between the CONDUIT model used for flight control design and evaluation, and the in-flight results. Figure 7 shows a similar comparison in the time domain, between the inflight and CONDUIT model responses to a longitudinal doublet input.

Pitch, roll and yaw bandwidths and phase delays were calculated from the flight test attitude responses, and are listed in Table 3. Performance of the RASCAL MFCL against the ADS-33E (PRF) ${ }^{19}$ handling-quality specifications for bandwidth and phase delay are shown in Figure 8. Although the pitch and roll axes have attitude-response command models, trim follow-up causes a rate-like response for steady-state inputs; ADS-33 specifies that for ACAH response types, bandwidth is defined by the $45-\mathrm{deg}$ phase margin frequency, while for rate-response systems, bandwidth is the lesser of the 45-deg phase margin bandwidth or the 6-dB gain margin bandwidth. Thus, as seen in Table 3, the gain margin bandwidths are applicable for the pitch and roll axes, and are significantly lower than the phase margin bandwidths.

The pitch response is Level 1, even for the aggressive Target Acquisition and Tracking mission task element (MTE). The roll response is Level 2 for the Target Acquisition and Tracking MTE, due to the level of phase delay; for other MTEs, including those with poor Useable Cue Environment (UCE) and divided-attention operations, the roll response is Level 1. The yaw response is Level 3 for Target Acquisition and Tracking and Level 2 for other MTEs. However, preliminary pilot evaluations have not faulted the yaw response as being especially sluggish, and the low yaw phase delay indicates the potential to increase the bandwidth by changing the command model characteristics, if it proves desirable. 

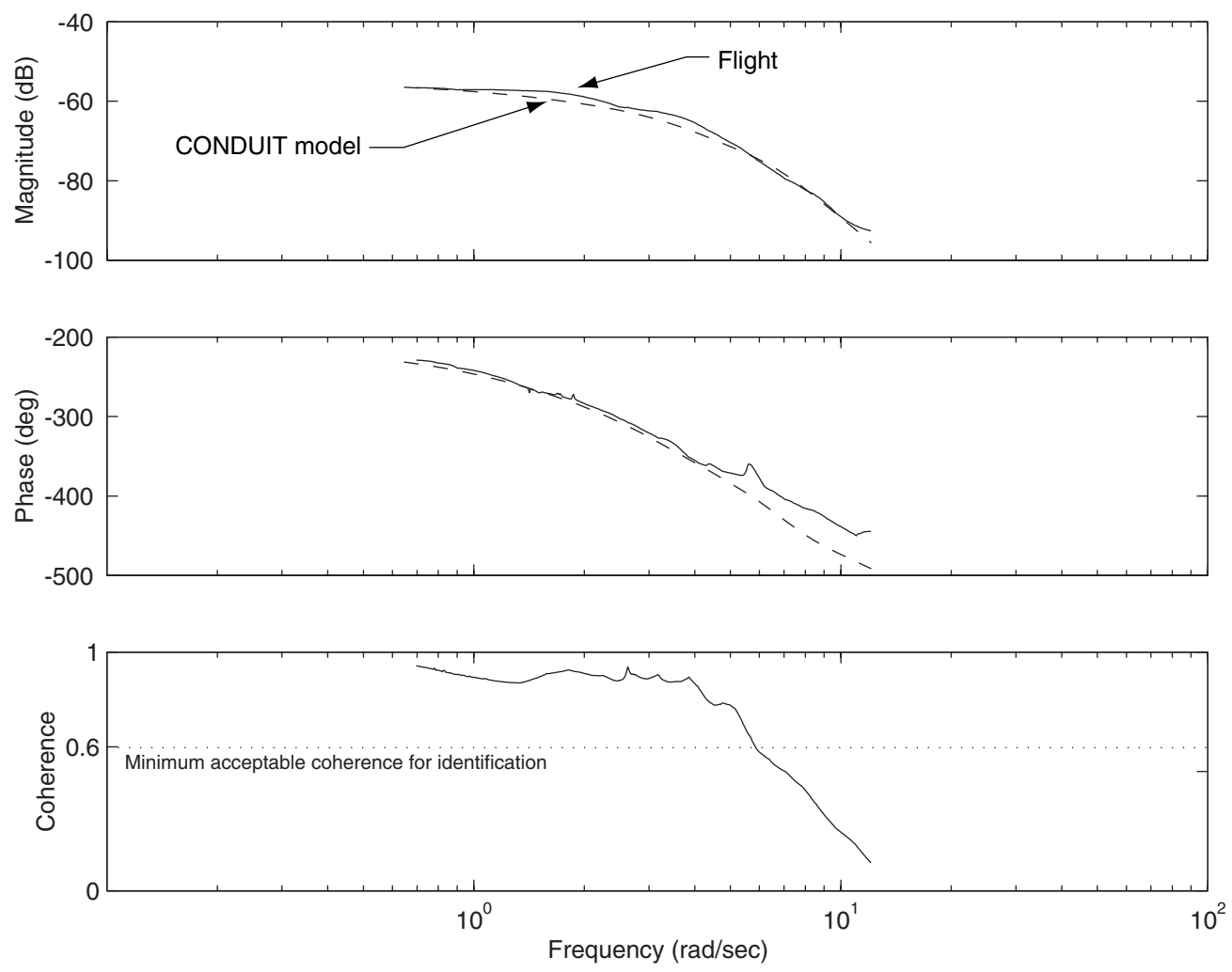

Figure 6. Pitch attitude frequency response $\left(\theta / \delta_{\text {lon }}\right)$ - Flight vs. CONDUIT model

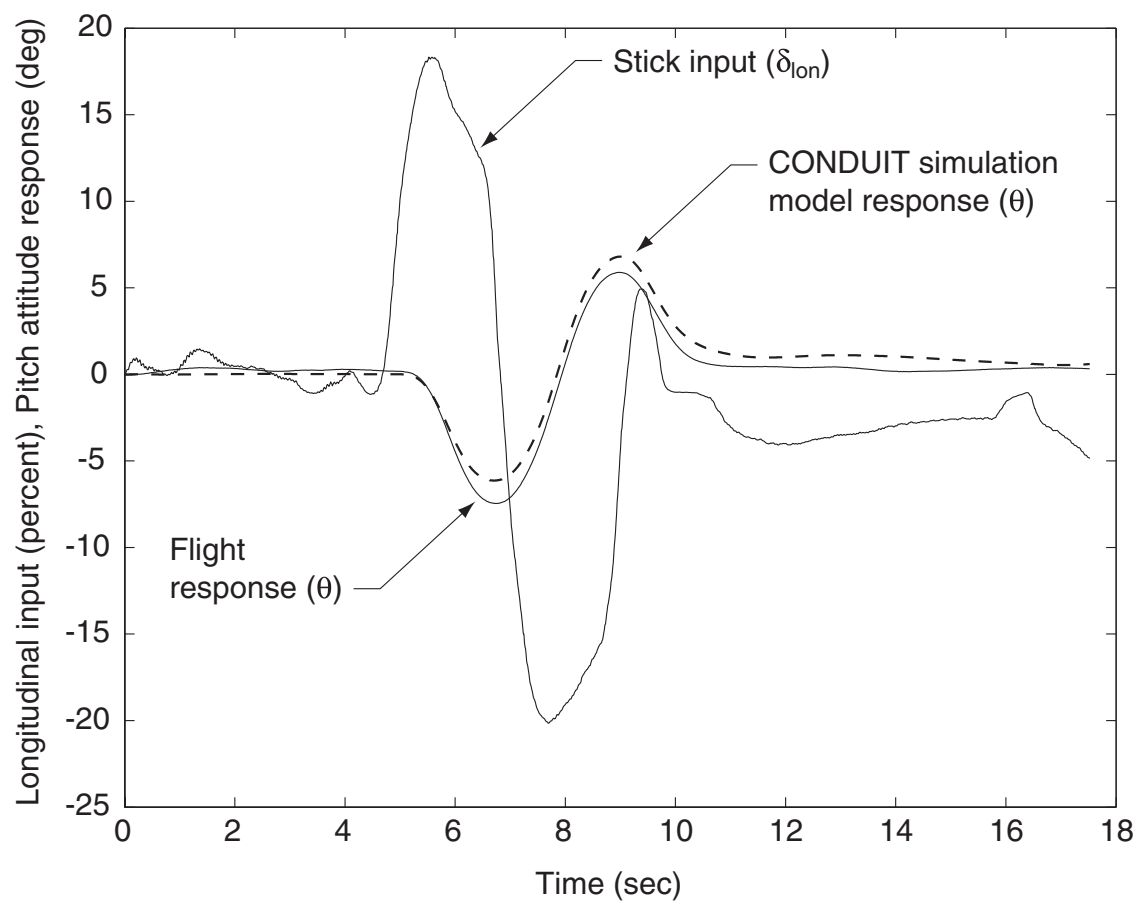

Figure 7. Pitch attitude time response $\left(\theta / \delta_{\text {lon }}\right)$ - Flight vs. CONDUIT model 
Table 3. Summary of identified bandwidth and phase delay values

\begin{tabular}{lccc}
\hline \hline Axis & $\begin{array}{c}\omega_{\mathrm{BW} \text { gain }}, \\
\mathrm{rad} / \mathrm{sec}\end{array}$ & $\begin{array}{c}\omega_{\mathrm{BW} \text { phase }}, \\
\mathrm{rad} / \mathrm{sec}\end{array}$ & $\tau_{\mathrm{p}}, \mathrm{sec}$ \\
\hline Pitch & 2.31 & 2.84 & 0.133 \\
Roll & 2.77 & 3.70 & 0.143 \\
Yaw & 3.65 & 1.50 & 0.083 \\
\hline Bandwidth frequencies per ADS-33 guidelines for \\
rate-response systems are shaded. \\
\hline \hline
\end{tabular}

As seen in both Figure 6 and Figure 8, the model predicts significantly more phase delay than seen in the flight response; this is due to the initial estimates used for sensor dynamics used in the model. The model has subsequently been updated to provide a better match to the flight data.

For a model-following control system, performance may be evaluated by how well the aircraft response tracks the command model, which for an in-flight simulator like RASCAL, might in fact represent a different flight vehicle. Figure 9 shows the aircraft pitch attitude response to the command model's attitude command, $\theta / \theta_{\mathrm{m}}$. The "perfect" response is unity, as derived in Eq. 1. Also plotted are the boundaries of the maximum unnoticeable additional dynamics (MUAD), which provide an indication of how pilots will perceive differences between the aircraft dynamics and the command model. $^{20}$ The aircraft response tracks the command model within the MUAD bounds, out to 2.5 $\mathrm{rad} / \mathrm{sec}$, above which the phase responses diverge. Above this frequency, the low-order inverse model $\mathrm{P}^{-1}(\mathrm{~s})$ does not attempt to cancel rotor lags and other high-order elements. Computing the equivalent time delay, from the $90 \mathrm{deg}$ phase lag at $10 \mathrm{rad} / \mathrm{sec}$,

$$
\tau=\frac{90^{\circ}}{57.3 \cdot 10 r / s}=0.157 \mathrm{~s}
$$

which is approximately the value predicted by the sum of system elements as listed in Table 1 .

Finally, low-order equivalent system (LOES) transfer functions were fitted to the flight data, to provide a simple linear representation of the characteristics of the closed-loop aircraft. Table 4 compares the identified values with the analytic command models. There is good agreement among the parameters. The delay captured by the LOES fit is comparable to that estimated in Table 1, and for the pitch axis, agrees closely with the value computed above. The low equivalent time delay of the yaw response reinforces the possibility mentioned earlier of increasing the yaw response bandwidth.

\section{Target Acquisition \& Tracking MTE}
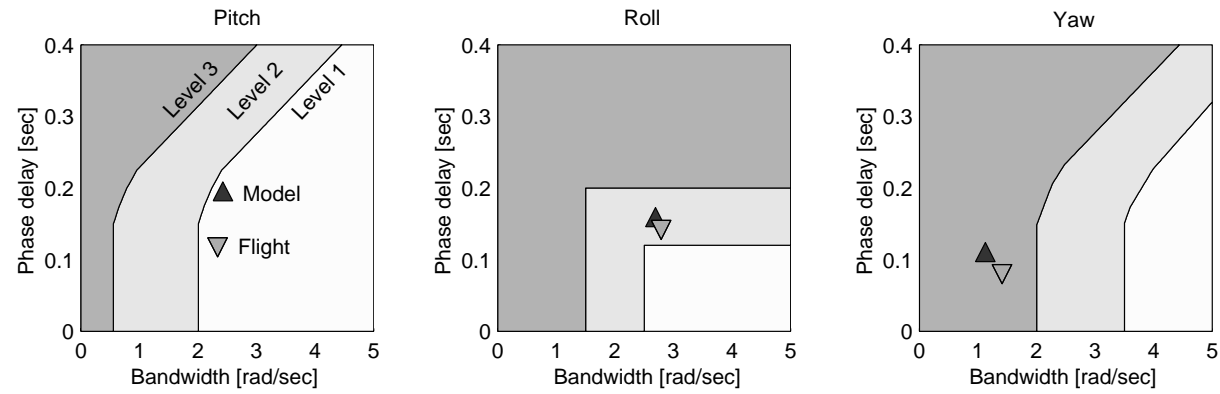

Other MTEs; UCE>1; Divided Attention
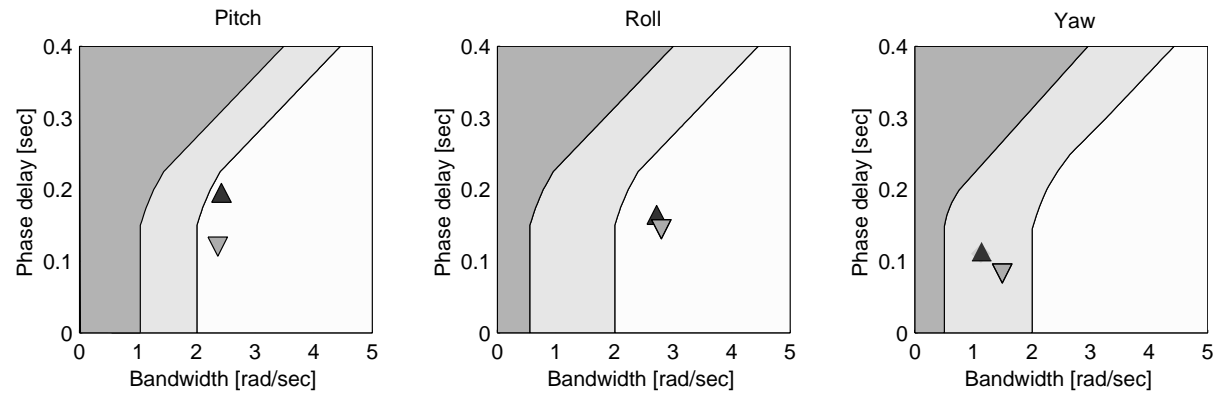

Figure 8. Bandwidth and phase delay results - hover 

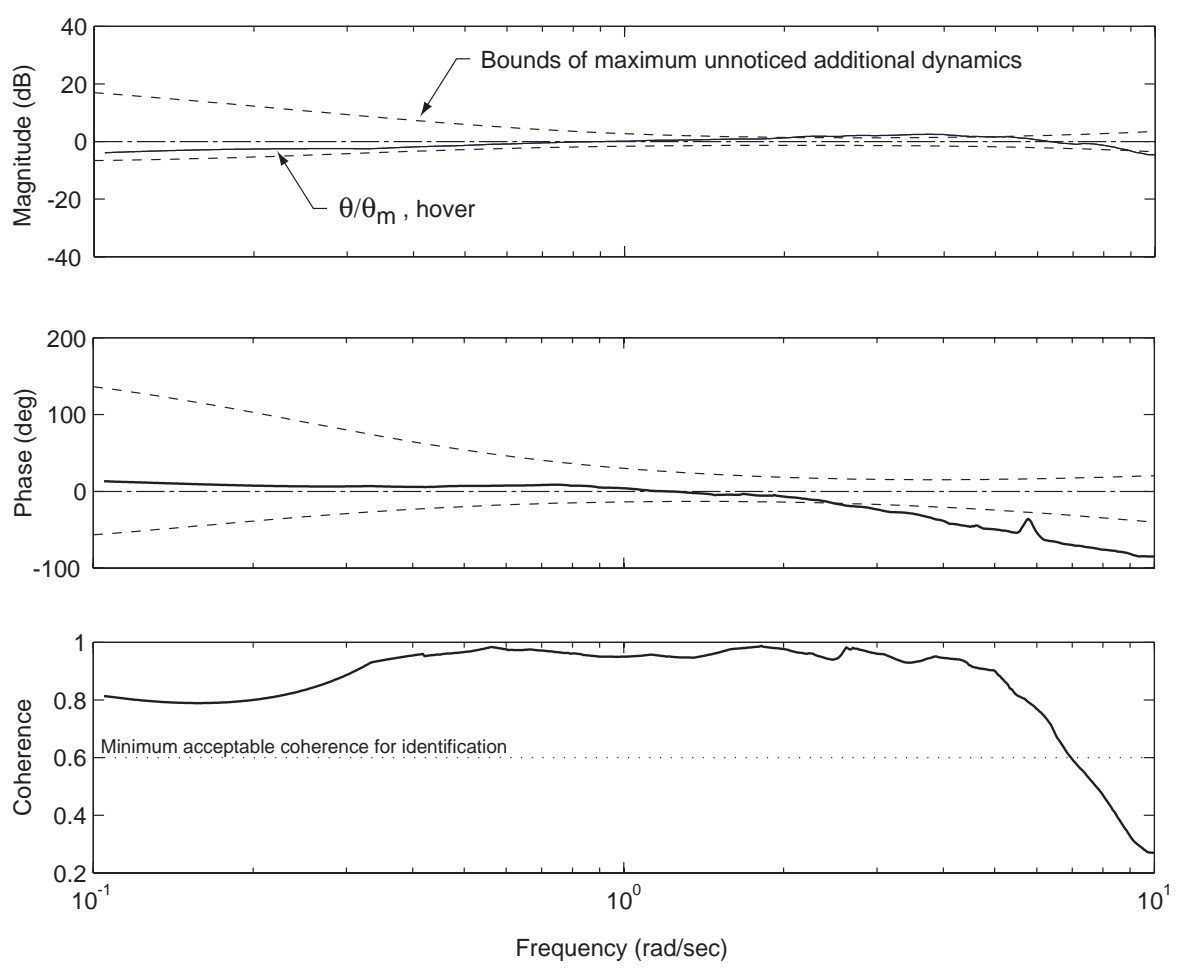

Figure 9. Pitch attitude response to command model output

Table 4. Summary of analytical command model transfer functions and identified equivalent-system transfer functions, hover

\begin{tabular}{lcc}
\hline \hline & $\begin{array}{c}\text { Analytical } \\
\text { Command } \\
\text { Model } \\
\text { Transfer } \\
\text { Function }\end{array}$ & $\begin{array}{c}\text { Low-order Fit to } \\
\text { Frequency Response } \\
\text { from Flight Data }\end{array}$ \\
\hline $\begin{array}{l}\text { Pitch } \\
\left(\theta_{\mathrm{m}} / \theta_{\mathrm{c}}\right)\end{array}$ & $\frac{4.31 \cdot(0.2)}{s \cdot[1.0,2.0]}$ & $\frac{4.25 \cdot(0.15)}{s \cdot[0.74,2.18]} \cdot e^{-0.153 s}$ \\
\hline $\begin{array}{l}\text { Roll } \\
\left(\phi_{\mathrm{m}} / \phi_{\mathrm{c}}\right)\end{array}$ & $\frac{6.45 \cdot(0.2)}{s \cdot[1.0,2.54]}$ & $\frac{7.55 \cdot(0.135)}{s \cdot[1.63,2.45]} \cdot e^{-0.158 s}$ \\
\hline $\begin{array}{l}\text { Yaw } \\
\left(\psi_{\mathrm{m}} / \psi_{\mathrm{c}}\right)\end{array}$ & $\frac{2.0}{s \cdot(2.0)}$ & $\frac{2.35}{s \cdot(2.4)} \cdot e^{-0.053 s}$ \\
\hline \hline
\end{tabular}

Table 5 compares the pitch attitude response of RASCAL to prior results obtained for the ADOCS aircraft, which used a similar model-following control law on the same JUH-60 aircraft as RASCAL. The comparison illustrates the $37 \%$ reduction in equivalent time delay achieved by using ten-year-newer technology in the RASCAL RFCS components.

* Note: Transfer functions shown in shorthand notation, wherein $(a)=(s+a) ;[\zeta, \omega]=\left(s^{2}+2 \zeta \omega s+\omega^{2}\right)$.
Table 5. Comparison of RASCAL and ADOCS equivalent time delays

\begin{tabular}{ccc}
\hline \hline & $\begin{array}{c}\text { Pitch } \\
\text { Command } \\
\text { Model }^{*}, \theta_{\mathrm{m}} / \theta_{\mathrm{c}}\end{array}$ & $\begin{array}{c}\text { Low-order Fit to } \\
\text { Flight Data }\end{array}$ \\
\hline ADOCS $^{15}$ & $\frac{4.0 \cdot(0.2)}{s \cdot[1.0,2.0]}$ & $\frac{5.26 \cdot(0.2)}{s \cdot[0.96,2.35]} \cdot e^{-0.244 s}$ \\
\hline RASCAL & $\frac{4.31 \cdot(0.2)}{s \cdot[1.0,2.0]}$ & $\frac{4.25 \cdot(0.15)}{s \cdot[0.74,2.18]} \cdot e^{-0.153 s}$ \\
\hline \hline
\end{tabular}

The results of development and testing of two different flight control law architectures for the RASCAL research helicopter demonstrated that the analysis/development model closely matched the aircraft. This result substantiates that flight control designs implemented on RASCAL will perform as expected, thereby contributing to the reduction in design cycle time already afforded by the use of the Army/NASA desktop-to-flight tools.

The RASCAL model-following control law performs well against the ADS-33E specifications for attitude bandwidth and phase delay in the pitch and roll axes. The yaw results would tend to indicate an unacceptably sluggish response, but pilot experience thus far is favorable. The disparity warrants further investigation, including evaluation against specific ADS-33E tasks. 
1 Dones, F., Dryfoos, J. B., McCorvey, D. L., and Hindson, W. S., An Advanced Fly-by-Wire Flight Control System Designed for Airborne Research Concept to Reality, proceedings of the $56^{\text {th }}$ Annual Forum of the American Helicopter Society, Virginia Beach, VA, May 2-4, 2000.

2 Fletcher, Jay W., A Model Structure for Identification of Linear Models of the UH-60 Helicopter in Hover and Forward Flight, NASA Technical Memorandum 110362 and US Army ATCOM Technical Report 95A-008, August 1995.

3 Tischler, M.B., Cauffman, M.G., FrequencyResponse Method for Rotorcraft System Identification: Flight Applications to BO-105 Coupled Rotor/Fuselage Dynamics, Journal of the American Helicopter Society, Vol 37, No 3, pgs 317, July 1992.

${ }^{4}$ Ballin, M.G., and Dalang-Secretan, M. A., Validation of the Dynamic Response of a Blade-Element UH-60 Simulation Model in Hovering Flight, proceedings of the $46^{\text {th }}$ Annual Forum of the American Helicopter Society, Washington, D.C., May 1990.

5 Colbourne, J.D., et al, Control Law Design and Optimization for Rotorcraft Handling Qualities Criteria Using CONDUIT, proceedings of the $55^{\text {th }}$ Annual Forum of the American Helicopter Society, Montreal, Canada, May 25-27, 1999.

6 Mansur, M. H., Frye, M., Mettler, B., Montegut, M., Rapid Prototyping and Evaluation of Control System Designs for Manned and Unmanned Applications, proceedings of the $56^{\text {th }}$ Annual Forum of the American Helicopter Society, Virginia Beach, VA, May 2-4, 2000.

7 Moralez, E. M., Hindson, W. S., Frost, C. R., Tucker, G. E., Arterburn, D. R., Kalinowski, K. F. and Dones, F., Flight Research Qualification of the Army/NASA RASCAL Variable-Stability Helicopter, $58^{\text {th }}$ Annual Forum of the American Helicopter Society, Montreal, Canada, June 2002.

8 Frost, C. R., Tischler, M. B., Bielefield, M., LaMontagne, T., Design and Test of Flight Control Laws for the Kaman BURRO Unmanned Aerial Vehicle, Presented at the AIAA Atmospheric Flight Mechanics Conference, Denver, CO, August 14-17, 2000.

9 Colbourne, J. D., Tischler, M. B., and Rodgers, K., Flight Control Design for an Unmanned Rotorcraft Program with a Rapid Development Schedule, proceedings of the $57^{\text {th }}$ Annual Forum of the American Helicopter Society, Washington, D. C., May 9-11, 2001.

${ }^{10}$ Lipera, L., Colbourne, J. D., Tischler, M. B., Mansur, H. M., Rotkowitz, M. C., and Patangui, P., The Micro Craft iSTAR Micro Air Vehicle: Control System Design and Testing, proceedings of the American
Helicopter Society 57th Annual Forum, Washington, D.C., May 2001.

${ }^{11}$ Hindson, W.S., Schroeder, J.A., Eshow, M.M., $A$ Pilot Rating Scale For Evaluating Failure Transients In Electronic Flight Control Systems, AIAA Atmospheric Flight Mechanics Conference, August 1990.

${ }^{12}$ Tischler, M. B., Digital Control of Highly Augmented Combat Rotorcraft, NASA TM-88346, May 1987, p. 98.

13 Department of Defense Interface Standard MILHDBK-1797, "Flying Qualities of Piloted Aircraft," 19 December 1997. Appendix A, p. 230.

${ }^{14}$ Dones, F., McManus, B., Ulmer, L., and Rediess, N., An Advanced Fly-by-Wire Flight Control System for the RASCAL Research Rotorcraft - Concept to Reality, $14^{\text {th }}$ AIAA/IEEE Digital Avionics Systems Conference, Cambridge, MA, November 5-9, 1995.

${ }^{15}$ Tischler, M. B., Fletcher, J. W., Morris, P. M., and Tucker, G. E., Flying Quality Analysis and Flight Evaluation of a Highly Augmented Combat Rotorcraft, AIAA Journal of Guidance, Control and Dynamics, Vol. 14, No. 5, pp. 954 - 963. September 1991.

${ }^{16}$ Gold, P., Dryfoos, J. B., Design and Pilot Evaluation of the RAH-66 Comanche Selectable AFCS Control Modes, in Proceedings of AHS Conference on Piloting Vertical Flight Aircraft, San Francisco, CA, January 20-22, 1993, pp. 5.39-5.46.

${ }^{17}$ Tischler, M. B., Digital Control of Highly Augmented Combat Rotorcraft, NASA TM-88346, May 1987, pp. 45-47.

18 Ringland, R. F. and Clement, W. F., Systems Definition Phase NAVTOLAND Rotary Wing Program, SH-2F Control Laws Development, Vol. 1. STI-TR-1177-1, Vol. 1, Systems Technology Inc., 1981. (Available from NASC as NADC-80251-60 or from COMNAVAIRDEVCEN.)

${ }^{19}$ United States Army Aviation Systems Command, "Handling Qualities Requirements for Military Rotorcraft," ADS-33E (PRF), St. Louis, MO, March 2000.

${ }^{20}$ Department of Defense Interface Standard MILHDBK-1797, "Flying Qualities of Piloted Aircraft," 19 December 1997. Appendix B, pp. 690-694. 